\title{
Reliability and Validity of the Persian Version of the Mini-Balance Evaluation Systems Test in Patients with Stroke
}

\author{
Soofia Naghdi · Noureddin Nakhostin Ansari • Bijan Forogh • \\ Maedeh Khalifeloo · Roshanak Honarpisheh • Amin Nakhostin-Ansari
}

Received: May 30, 2020 / Published online: August 14, 2020

(c) The Author(s) 2020

\section{ABSTRACT}

Background: Stroke can cause balance disorders, which often lead to falls and fall-related injuries. The Mini-Balance Evaluation Systems Test (Mini-BESTest) is a balance test that has been recently translated into Persian. The reliability and validity of the Persian version of Mini-BESTest have not been assessed in patients with stroke.

Objectives: To assess the reliability and validity of the Persian version of the Mini-BESTest in patients with stroke.

Methods: A cross-sectional study was designed. Thirty patients with stroke participated in this study. Patients were tested using the Mini-

Digital Features To view digital features for this article go to https://doi.org/10.6084/m9.figshare.12733061

S. Naghdi · N. Nakhostin Ansari · B. Forogh Neuromusculoskeletal Research Center, Iran University of Medical Sciences, Tehran, Iran

S. Naghdi · N. Nakhostin Ansari · M. Khalifeloo ·

R. Honarpisheh

Department of Physiotherapy, School of

Rehabilitation, Tehran University of Medical

Sciences, Tehran, Iran

S. Naghdi · N. Nakhostin Ansari · A. NakhostinAnsari ( $\square)$

Sports Medicine Research Center, Neuroscience Institute, Tehran University of Medical Sciences, Tehran, Iran

e-mail: a-nansari@alumnus.tums.ac.ir
BESTest according to the Persian instructions, and two raters independently rated each patient's performance. Each patient was matched with a healthy adult in the terms of age and gender. Healthy subjects were also tested for discriminative validity.

Results: There was excellent correlation between two raters on the Persian version of the Mini-BESTest total scores $\left(r_{\text {Pearson }}=0.98\right.$, $P<0.001)$ and its sections $\left(r_{\text {Pearson }}>0.9\right)$. There was a significant difference between stroke patients and healthy subjects confirming the discriminative validity of the Persian version of the Mini-BESTest $(19.4 \pm 5.4$ vs. $24.8 \pm 2.3$, $P<0.001$ ).

Limitations: We only assessed stroke patients, and the results may not be generalized to other patients with balance deficits.

Conclusions: The Persian version of the MiniBESTest is a reliable and valid tool for balance evaluation of stroke patients.

Keywords: Balance; Mini-BESTest; Reliability; Validity 


\section{Key Summary Points}

The Mini-BESTest has been adapted to the Persian language but has not been evaluated for reliability and validity.

This study evaluated the inter-rater and discriminative validity of the Persian Mini-BESTest in balance evaluation of patients with stroke.

The Persian Mini-BESTest is a reliable and valid tool for balance evaluation of patients with stroke.

Persian-speaking clinicians can use the Persian Mini-BESTest in the clinic and research to assess balance in patients with stroke.

\section{INTRODUCTION}

Annually about $84.16-103.23$ per 100,000 Iranians experience a stroke [1]. Most stroke patients will suffer from balance disorder and postural instability because of muscle weakness and sensory problems $[2,3]$. Change in balance reflexes [4], sensory organization disorders [5] and alterations in attention requirements during postural tasks [6] all play roles in this balance deficit. Balance disorder can be a major risk factor for falling [7], which can lead to fall-related injuries [8]. A comprehensive balance assessment can guide treatment for a suitable approach that can reduce the balance deficits and fall risk [9].

Several tools can be used for balance assessment. The Four Square Step Test (FSST) [10], Timed Up and Go (TUG) [11], Dynamic Gait Index (DGI) [12] and Berg Balance Scale (BBS) [13] are useful tests for balance assessment, but they have limitations [14]. TUG and FSST are single-task tests that are useful for screening; however, they cannot comprehensively assess the balance systems. The scoring system is not clear for the DGI. The BBS does not assess dynamic balance or have a ceiling effect [14].

The Balance Evaluation Systems Test (BESTest) is a new tool that assesses different balance systems including biomechanical constraints, stability limits/verticality, anticipatory postural adjustments, postural responses, sensory orientation and gait stability. The BESTest can detect the system responsible for the balance impairment and can subsequently direct treatment [15]. BESTest's reliability, validity, sensitivity and specificity have been demonstrated in patients with sub-acute stroke [16]. BESTest takes 20-35 min to administer [15], which reduces its clinical feasibility.

The Mini-BESTest is the shorter version of the BESTest, which takes 10-15 min to administer. Using Factor and Rasch analyses, 14 of the 36 items of the BESTest, which mostly represent dynamic balance, have been selected for the Mini-BESTest [17]. The Mini-BESTest is valid and reliable for assessing patients with chronic stroke and is more accurate than the BBS for identifying fallers post-stroke [18].

Although the original English version of the Mini-BESTest is a valid and reliable tool in assessing patients with balance disorders, the reliability and validity of the Persian version has not been evaluated in patients with stroke. The aim of the present study is to evaluate the validity and reliability of the Persian MiniBESTest in patients with stroke. We hypothesized that the Persian version of the MiniBESTest is a reliable and valid tool for balance evaluation of patients with stroke.

\section{METHODS}

\section{Design}

This cross-sectional study was approved by the Research Council of the Neuromusculoskeletal Research Center and the Ethics Committee of Iran University of Medical Sciences (ethics code: IR.IUMS.REC1396.311411). The procedure was completely explained to each patient, and written informed consent for participation in the study was obtained. This study was 
performed in accordance with the Helsinki Declaration of 1964 and its later amendments.

\section{Participants}

A group of patients with chronic stroke participated in the study. Each patient was matched with a healthy adult in terms of age and gender. Our inclusion criteria for the patient group were: (1) diagnosis of stoke, (2) ability to live independently in the community, (3) ability to speak Persian, (4) ability to follow a three-step command, (5) ability to walk $6 \mathrm{~m}$ without aid, (6) no history of pathologic vertigo, (7) no history of pathologic faint, (8) no history of other vascular, musculoskeletal or neurologic problems that affect the balance and (9) no use of drugs affecting the balance in the past $48 \mathrm{~h}$. Patients were excluded if they did not complete the test or did not agree to participate in the study.

Our inclusion criteria for the neurologic healthy group were: (1) living independently in the community, (2) ability to speak Persian, (3) ability to perform the commands, (4) ability to walk $6 \mathrm{~m}$ without aid, (5) giving consent, no history of pathologic faint or vertigo, (6) no use of drugs that affect balance in the past $48 \mathrm{~h}$ and (7) no history of medical conditions such as neurologic or musculoskeletal disorders that affect balance.

\section{Procedure}

The study took place in the neurologic physiotherapy clinic of the rehabilitation faculty of Tehran University of Medical Sciences. The environment was quiet and separated from other patients. Before performing the test, the demographic characteristics of each patient were recorded.

\section{Reliability}

Two physical therapists and a medical student participated in the study. Prior to the study initiation, raters participated in an educational session on the Mini-BESTest held by the first author. The session included a review of the study procedure, watching the BESTest training video provided by Prof. Horak, reading the testing instructions and practicing.

For the inter-rater reliability, two trained physical therapists scored the test for each patient in a session. For assessing each patient, one rater administered the test. After the patients had performed each item, the raters independently scored the performance on the test item according to the Mini-BESTest criteria. Inter-rater reliability was determined for the total scores and section scores. The raters were blinded to their ratings, and no discussion of the scores assigned was allowed.

\section{Validity}

To evaluate whether the Persian Mini-BESTest can distinguish between healthy adults and stroke patients (discriminative validity), each patient was matched with a healthy adult according to age and gender. A medical student administered the test and rated the performance of all the healthy subjects. For assessing the discriminative validity, the total MiniBESTest scores of patients and healthy subjects were compared. The total Mini-BESTest scores assigned for patients in the inter-rater reliability phase of the study were used, and scores provided by one of the raters were randomly selected for comparison.

\section{Outcome Measures}

The Mini-BESTest is a clinical balance test consisting of 4 sections and 14 items (Table 1). Each item is scored from 0 (worst performance) to 2 (best performance). The total score is 28 .

\section{Sample Size and Data Analysis}

According to the guidelines we included 30 patients with stroke and 30 neurologically healthy subjects for reliability and discriminative validity assessment [19]. The percentage of male and females among patients was calculated. Mean and standard deviation (SD) for demographic and outcome variables were calculated. Kolmogorov-Smirnov test was used to determine normality. Pearson's correlation coefficients were used to assess the inter-rater 
Table 1 Sections and items of the Mini-BESTest

\begin{tabular}{lll}
\hline Test & Section & Item \\
\hline Mini-BESTest & Sit to stand & Rise to toes \\
& Stand on one leg \\
& Reactive postural control & Compensatory stepping correction-forward \\
& Compensatory stepping correction-backward \\
& Sensory orientation & Compensatory stepping correction-lateral \\
& Stance (feet together); eyes open, firm surface \\
& Stance (feet together); eyes closed, foam surface \\
& Inline-eyes closed \\
& Change in gait speed \\
& Walk with head turns- horizontal \\
& Walk with pivot turns \\
& Step over obstacles \\
& Timed Up and Go with dual task
\end{tabular}

reliability. Correlation values $<0.4$ were interpreted as poor, between 0.4 and 0.75 as moderate and $>0.75$ as excellent [20]. To assess the discriminative validity, the independent $T$ test or the Mann-Whitney $U$ test was used depending on the normality of the data. SPSS software (version 16 for Windows, SPSS Inc., Chicago, Il) was used for analyses.

Table 2 Demographic characteristics of patients

\begin{tabular}{lcc}
\hline Variable & Mean (SD) & \multicolumn{1}{c}{ Range } \\
\hline Age (years) & $54.2(16.1)$ & $16-86$ \\
Height $(\mathrm{cm})$ & $167(9.4)$ & $150-188$ \\
Weight $(\mathrm{kg})$ & $71.6(13.3)$ & $51-101$ \\
BMI & $25.6(4.2)$ & $19.4-36.9$ \\
Time since stroke (months) & $39.9(48.1)$ & $1-156$ \\
\hline
\end{tabular}

\section{RESULTS}

Of the 30 patients, 17 were male $(56.7 \%)$ and 13 female $(43.3 \%)$. Fourteen patients had right hemiplegia (46.7\%) and 16 had left hemiplegia $(53.3 \%)$. Other demographic data are shown in the Table 2 .

\section{Reliability}

Mean and SD of the Persian Mini-BESTest total score, section scores and correlation coefficients between two raters are shown in Table 3 . The Persian Mini-BESTest total scores had excellent inter-rater reliability for the total score $\left(r_{\mathrm{p}}=\right.$ 0.98, $P<0.001$ ) (Fig. 1) and section scores $\left(r_{\mathrm{p}}=0.91-1.0\right)$.

\section{Discriminative Validity}

Mann-Whitney $U$ test showed significant differences in the Persian Min-BESTest total score between patients with stroke (mean 19.4 and SD 
Table 3 Mean and standard deviation (SD) of total and section scores for the Persian Mini-BESTest rated by two raters and correlation between their scores

\begin{tabular}{llll}
\hline & Rater 1, mean $(\mathbf{S D})$ & Rater 2, mean $(\mathbf{S D})$ & Pearson's correlation $(\boldsymbol{P}$ value $)$ \\
\hline Anticipatory & $3.5(1.3)$ & $3.5(1.3)$ & $0.96(<0.001)$ \\
Reactive postural control & $3.2(2)$ & $3.5(2.1)$ & $0.91(<0.001)$ \\
Sensory orientation & $5.8(0.3)$ & $5.8(0.3)$ & $1.0(<0.001)$ \\
Dynamic gait & $6.8(2.5)$ & $6.8(2.4)$ & $0.98(<0.001)$ \\
Total score & $19.4(5.4)$ & $19.7(5.5)$ & $0.98(<0.001)$ \\
\hline
\end{tabular}

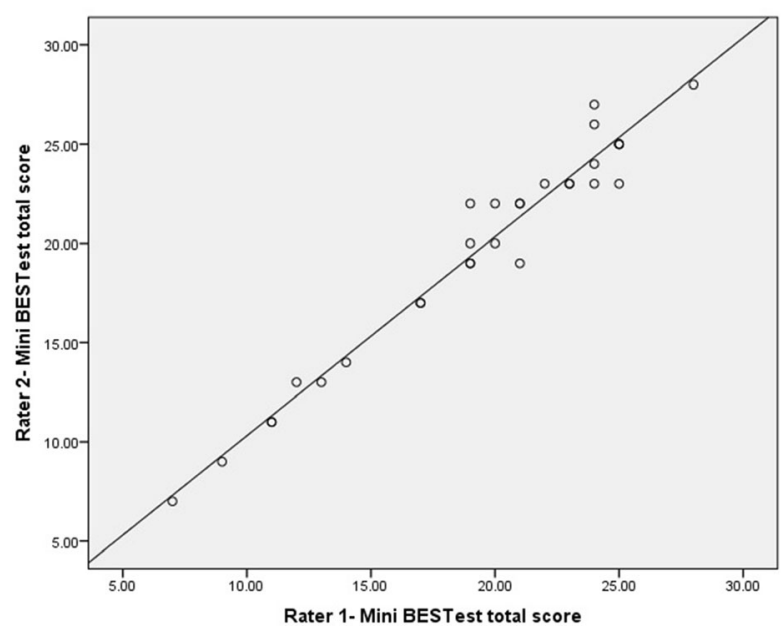

Fig. 1 Scatter plot for the Persian Mini-BESTest total scores assigned by two raters $\left(r_{\mathrm{p}}=0.98, P<0.001\right)$

5.4) and healthy subjects (mean 24.8 and SD 2.3), $P<0.001$.

\section{DISCUSSION}

This study investigated the inter-rater reliability and validity of the Persian Min-BESTest in patients with stroke and demonstrated that the Persian version of the Mini-BESTest had excellent inter-rater reliability and discriminative validity in distinguishing between patients with stroke and healthy subjects.

Our results for inter-rater reliability are in line with those of Tsang et al. [18] as they found that the original version of the Mini-BESTEST had excellent inter-rater reliability for evaluating patients with chronic stroke (ICC 0.93-0.99). Another study found that the MiniBESTest had excellent inter-rater reliability in a group of patients with balance disorders (ICC 0.98) [21]. This excellent inter-rater reliability found with the Persian Mini-BESTest in patients with chronic stroke is comparable to those demonstrated for the BESTest (ICC 0.99) [16] and BBS (ICC 0.97-0.98) [13]. A review on the psychometric properties of the Mini-BESTest found excellent inter-rater reliability (ICC between 0.86-0.99) [22]. Using a stopwatch for objective scoring of 5 out of 14 items and clear instructions provided for both patients and raters might play a role in the high reliability of the Persian Mini-BESTest. Before the study, both of our raters had no experience with using the Mini-BESTest. The excellent inter-rater reliability of the Persian Mini-BESTest indicates that the two raters' lack of experience with the Persian MinBESTest did not affect the level of reliability, and the Persian Mini-BESTest was reliable even with novice raters.

We found that all sections of the Persian Mini-BESTest had excellent inter-rater reliability in testing patients with stroke. A previous study with patients with stroke reported adequate to excellent inter-rater reliability for all the test items [18]. In this study, the highest agreement $(100 \%)$ between the two raters was observed for the sensory orientation section. The stationary exercises only being included in the sensory orientation section and criteria for scoring items being based on the time patients needed to complete a task could be the reasons why the two raters had perfect agreement. This finding is 
in agreement with a previous report in patients with Parkinson's disease that also found the highest agreement for the sensory orientation [23].

We demonstrated a significant difference between patients with stroke and healthy subjects in the total score, confirming the discriminative validity of the Persian Mini-BESTest. This finding is in line with previous reports in patients with stroke [18] and different patient groups and healthy older adults [22]. Our findings indicate the ability of the Persian version of the Mini-BESTest to discriminate between stroke patients with balance disorder and healthy subjects.

This study had limitations. First, the test was administered by one of the raters while the second rater concurrently observed and scored the balance performance. This might reduce the generalizability of the findings to the clinical context. Second, we only examined stroke patients; thus, the results of the present study may not be generalizable to other diseases causing balance disorders. Further studies investigating the reliability and validity of the Persian version of the Mini-BESTest in patients with different balance disorder etiologies are suggested. Third, we only evaluated the interrater reliability and discriminative validity of the Persian Mini-BESTest; future studies are needed to evaluate the other aspects of reliability and validity. Fourth, responsiveness to evaluating the sensitivity of the Persian MiniBESTest to detect changes over time after an intervention and to determine minimally clinically important change was not investigated in this study. Fifth, the sensitivity and specificity of the Persian version of the Mini-BESTest in predicting future falls were not investigated in our study.

\section{CONCLUSION}

This study demonstrated that the Persian version of the Mini-BESTest has excellent reliability and validity in evaluating balance deficits. The Persian version of the Mini-BESTest, a useful and quick clinical test, can be used by clinicians for assessing balance deficits of patients with stroke in Persian-speaking countries.

\section{ACKNOWLEDGEMENTS}

We thank all subjects who participated in the study.

Funding. This study was supported by the Neuromusculoskeletal Research Center, Iran University of Medical Sciences (grant no. 96-03217-31141). No funding or sponsorship was received for the publication of this article.

Authorship. All named authors meet the International Committee of Medical Journal Editors (ICMJE) criteria for authorship for this article, take responsibility for the integrity of the work as a whole, and have given their approval for this version to be published.

Disclosures. Soofia Naghdi, Bijan Forogh, Maedeh Khalifeloo, Roshanak Honarpisheh, Noureddin Nakhostin Ansari, and Amin Nakhostin-Ansari declare that they have nothing to disclose.

Compliance with Ethics Guidelines. This study was performed in accordance with the Helsinki Declaration of 1964 and its later amendments. All subjects provided written informed consent to participate in the study. The study protocol was approved by Ethics Committee of the Iran University of Medical Sciences (ethics code: IR.IUMS.REC1396.311411).

Data Availability. The datasets generated during and analyzed during the current study are available from the corresponding author on reasonable request.

Open Access. This article is licensed under a Creative Commons Attribution-NonCommercial 4.0 International License, which permits any non-commercial use, sharing, adaptation, distribution and reproduction in any medium or format, as long as you give appropriate credit 
to the original author(s) and the source, provide a link to the Creative Commons licence, and indicate if changes were made. The images or other third party material in this article are included in the article's Creative Commons licence, unless indicated otherwise in a credit line to the material. If material is not included in the article's Creative Commons licence and your intended use is not permitted by statutory regulation or exceeds the permitted use, you will need to obtain permission directly from the copyright holder. To view a copy of this licence, visit http://creativecommons.org/licenses/by$\mathrm{nc} / 4.0 /$.

\section{REFERENCES}

1. Ghandehari K, Sharifi A, Nikbin Z, Fadaei S, Meybodi MA, Moshfegh M, et al. Clinical evaluation of patients with migraine induced stroke in Mashhad, Iran. ARYA Atheroscler. 2010;6(3):90-3.

2. Perlmutter S, Lin F, Makhsous M. Quantitative analysis of static sitting posture in chronic stroke. Gait Posture. 2010;32(1):53-6.

3. Tyson SF, Hanley M, Chillala J, Selley A, Tallis RC. Balance disability after stroke. Phys Ther. 2006;86(1):30-8.

4. Marigold DS, Eng JJ. Altered timing of postural reflexes contributes to falling in persons with chronic stroke. Exp Brain Res. 2006;171(4):459-68.

5. Bonan IV, Colle FM, Guichard JP, Vicaut E, Eisenfisz $\mathrm{M}$, TranBaHuy $\mathrm{P}$, et al. Reliance on visual information after stroke. Part I: Balance on dynamic posturography. Arch Phys Med Rehabil. 2004;85(2): 268-73.

6. Brown LA, Sleik RJ, Winder TR. Attentional demands for static postural control after stroke. Arch Phys Med Rehabil. 2002;83(12):1732-5.

7. Lamb SE, Ferrucci L, Volapto S, Fried LP, Guralnik JM, Women's $\mathrm{H}$, et al. Risk factors for falling in home-dwelling older women with stroke: the Women's Health and Aging Study. Stroke. 2003;34(2):494-501.

8. Mancini M, Horak FB. The relevance of clinical balance assessment tools to differentiate balance deficits. Eur J Phys Rehabil Med. 2010;46(2):239-48.
9. Goljar N, Giordano A, Schnurrer Luke Vrbanic T, Rudolf M, Banicek-Sosa I, Albensi C, et al. Rasch validation and comparison of Slovenian, Croatian, and Italian versions of the Mini-BESTest in patients with subacute stroke. Int J Rehabil Res. 2017;40(3): 232-9.

10. Blennerhassett JM, Jayalath VM. The Four Square Step Test is a feasible and valid clinical test of dynamic standing balance for use in ambulant people poststroke. Arch Phys Med Rehabil. 2008;89(11):2156-61.

11. Salbach NM, Mayo NE, Higgins J, Ahmed S, Finch LE, Richards CL. Responsiveness and predictability of gait speed and other disability measures in acute stroke. Arch Phys Med Rehabil. 2001;82(9): 1204-12.

12. Jonsdottir J, Cattaneo D. Reliability and validity of the dynamic gait index in persons with chronic stroke. Arch Phys Med Rehabil. 2007;88(11): 1410-5.

13. Berg K, Wood-Dauphinee S, Williams JI. The Balance Scale: reliability assessment with elderly residents and patients with an acute stroke. Scand J Rehabil Med. 1995;27(1):27-36.

14. Pollock C, Eng J, Garland S. Clinical measurement of walking balance in people post stroke: a systematic review. Clin Rehabil. 2011;25(8):693-708.

15. Horak FB, Wrisley DM, Frank J. The Balance Evaluation Systems Test (BESTest) to differentiate balance deficits. Phys Ther. 2009;89(5):484-98.

16. Chinsongkram B, Chaikeeree N, Saengsirisuwan V, Viriyatharakij N, Horak FB, Boonsinsukh R. Reliability and validity of the Balance Evaluation Systems Test (BESTest) in people with subacute stroke. Phys Ther. 2014;94(11):1632-43.

17. Franchignoni F, Horak F, Godi M, Nardone A, Giordano A. Using psychometric techniques to improve the Balance Evaluation Systems Test: the mini-BESTest. J Rehabil Med. 2010;42(4):323-31.

18. Tsang CS, Liao LR, Chung RC, Pang MY. Psychometric properties of the Mini-Balance Evaluation Systems Test (Mini-BESTest) in community-dwelling individuals with chronic stroke. Phys Ther. 2013;93(8):1102-15.

19. Koo TK, Li MY. A guideline of selecting and reporting intraclass correlation coefficients for reliability research. J Chiropr Med. 2016;15(2):155-63.

20. Roach K. Measurement of health outcomes: reliability, validity and responsiveness. J Prosthet Orthot. 2006;18(1S):8-12. 
21. Godi M, Franchignoni F, Caligari M, Giordano A, Turcato AM, Nardone A. Comparison of reliability, validity, and responsiveness of the mini-BESTest and Berg Balance Scale in patients with balance disorders. Phys Ther. 2013;93(2):158-67.

22. Di Carlo S, Bravini E, Vercelli S, Massazza G, Ferriero G. The Mini-BESTest: a review of psychometric properties. Int J Rehabil Res. 2016;39(2):97-105.
23. Löfgren N, Lenholm E, Conradsson D, Ståhle A, Franzén E. The Mini-BESTest-a clinically reproducible tool for balance evaluations in mild to moderate Parkinson's disease? BMC Neurol. 2014;14(1):235. 